\title{
PRAME gene expression profile in medulloblastoma
}

\author{
Tânia Maria Vulcani-Freitas 1,3, Nasjla Saba-Silva', Andréa Cappellano', \\ Sérgio Cavalheiro², Sílvia Regina Caminada de Toledo ${ }^{1,3}$
}

\begin{abstract}
Medulloblastoma is the most common malignant tumors of central nervous system in the childhood. The treatment is severe, harmful and, thus, has a dismal prognosis. As PRAME is present in various cancers, including meduloblastoma, and has limited expression in normal tissues, this antigen can be an ideal vaccine target for tumor immunotherapy. In order to find a potential molecular target, we investigated PRAME expression in medulloblastoma fragments and we compare the results with the clinical features of each patient. Analysis of gene expression was performed by real-time quantitative PCR from 37 tumor samples. The Mann-Whitney test was used to analysis the relationship between gene expression and clinical characteristics. Kaplan-Meier curves were used to evaluate survival. PRAME was overexpressed in $84 \%$ samples. But no statistical association was found between clinical features and PRAME overexpression. Despite that PRAME gene could be a strong candidate for immunotherapy since it is highly expressed in medulloblastomas.
\end{abstract}

Key words: PRAME, gene expression, medulloblastoma, immunotherapy.

\section{Perfil de expressão do gene PRAME em meduloblastoma}

\section{RESUMO}

Meduloblastoma é o tumor maligno mais comum em sistema nervoso central na infância. O tratamento é agressivo e o prognóstico é restrito. Como PRAME está presente em vários tumores, incluindo meduloblastoma, e possui baixa expressão em tecidos normais, este antígeno pode ser ideal na imunoterapia. A fim de encontrar um potencial alvo molecular, investigamos a expressão PRAME em fragmentos de meduloblastoma e comparamos os resultados com as características clínicas de cada paciente. Análise da expressão do gene foi realizada por PCR real-time quantitativo em 37 amostras de tumor. O teste de MannWhitney foi utilizado para análise da relação entre a expressão do gene e características clínicas e teste de Kaplan-Meier para avaliar a sobrevida. PRAME teve superexpresssão em 84\% amostras, mas não houve nenhuma relação estatística entre as características clínicas e superexpressão de PRAME. Apesar disso, o gene PRAME poderia ser um forte candidato para a imunoterapia, pois é altamente expresso em meduloblastomas.

Palavras-chave: PRAME, expressão gênica, meduloblastoma, imunoterapia.

\section{Correspondence}

Silvia Regina Caminada de Toledo

Rua Botucatu $743 / 8^{\circ}$ andar

04023-062 São Paulo SP - Brasil

E-mail: silviatoledo@graacc.org.br

\section{Support}

GRAACC/ CAPES/ FAPESP N 04/12133-6

Received 12 May 2010

Received in final form 7 July 2010

Accepted 15 July 2010
Medulloblastoma (MB) is the most common malignant tumors of central nervous system (CNS) and is a tumor highly aggressive ${ }^{1-3}$. Despite of the multimodal therapeutic regimens involving surgery, radiotherapy and chemoratherapy, the treatment carries a dismal prognosis and frequently results in neurological de- velopment and growth deficit, and endocrine dysfunction ${ }^{1,2}$.

Over the decades, several categories of antigens were found, including uniquely mutated antigens (e.g. p53), viral antigens (e.g. human papillomavirus antigens in cervical cancer), and differentiation antigens (e.g. CD20 in B-cell lympho- 
ma). More recently, a new category of antigen, namely the cancer/testis (CT) antigen, has emerged to be a unique group of antigen that could potentially be important antigen targets for antigen-specific cancer immunotherapy. For tumor antigens to be potential immunotherapeutic targets, the antigen must have no or highly restricted expression in normal tissues so that autoimmunity can be prevented ${ }^{4}$.

Currently, researches have been focused in the identification of tumor antigens in order to develop efficient therapeutic strategy. The new strategy is find ideal tumor antigens to apply as vaccine targets for immunotherapy ${ }^{5}$. However, it is still rare to find a suitable antigen for specific targeting and its identification remains a hard task. Immunotherapy against brain tumors presents unique challenges since the brain is considered an immune privileged site. However, recent studies demonstrated that the immune cells have access to the brain in spite of the blood-brain barrier ${ }^{6,7}$. Within malignant brain tumors the blood-brain barrier is generally considered non-functional. Progress, in our understanding, of immune responses to CNS tumors have already led to novel clinical applications ${ }^{8}$. Immunotherapy is an attractive therapeutic option for pediatric cancer patients because of its mild toxicity, and because the child's immune system is more potent and flexible compared to adults ${ }^{9,10}$. However, implementation of immunotherapy in pediatric oncology has been hampered by the lack of known tumor-specific antigens on pediatric tumors ${ }^{11}$.

One of these antigens, much studied in leukemia ${ }^{12-17}$, is tumor antigen PRAME (Preferentially Expressed Antigen in Melanoma). It was first discovered in a patient with melanoma and it was responsible for triggering cytotoxic T-cell-mediated immune response by autologous lymphocytes ${ }^{18}$. PRAME is frequently express in several solid tumors including neuroblastoma and medulloblastoma, but not or weak in normal tissues ${ }^{19,20}$. In neuroblastoma, $P R A M E$ expression is very commom and its overexpression is associated with advanced disease stage and poor prognostic ${ }^{20}$.

The aim of this study was to analyze PRAME gene expression in pediatric $M B$. We report the results of a quantitative real-time PCR analysis of the PRAME expression and compare with the clinical features of these patients.

\section{METHOD}

\section{Patients}

We selected $37 \mathrm{MBs}$ samples from patients (median age: 8 years) attending the Pediatric Oncology Institute (IOP)/Grupo de Apoio ao Adolescente e a Criança com Câncer (GRAACC) - Federal University of São Paulo (UNIFESP) - Brazil. Two normal brain samples, unrelated to pathological condition served as a tissue-specific expression control. Informed consent was obtained from all patients/guardians according to the University's IRB (CEP/UNIFESP No1120/01). All MB patients were classified according to Chang et al. ${ }^{21}$, as follows: $M$ stage include M0 (no evidence of disseminated disease), M1 (tumor cells identified by cerebrospinal fluid (CSF) cytology only), M2 (intracranial metastatic tumor detectable by computed tomography $(\mathrm{CT})$ or magnetic resonance imaging (MRI) and M3 (spinal metastatic tumor detectable by CT myelography or spine MRI); and the current WHO (World Health Organization) classification of CNS tumors was used to define the following histopathological variants of medulloblastoma: classic, desmoplastic/ nodular, anaplasic and large-cell medulloblastoma ${ }^{22}$.

\section{RNA extraction and CDNA synthesis}

Total RNA was isolated from frozen samples pulverized under nitrogen liquid and extracted using TRIzol reagent (Invitrogen, Carlsbad, CA, USA). To reduce the risk of genomic DNA contamination, DNase treatment was performed using deoxyribonuclease I Amplification Grade (Invitrogen, Carlsbad, CA, USA). The concentration of RNA was determined by spectrophotometry and total RNA integrity was monitored by visualization of ribosomal RNAs (28S and 18 ) on $1 \%$ agarose gel. One microgram of total RNA derived from $37 \mathrm{MB}$ samples was reverse-transcribed using the SuperScript III Reverse Transcriptase Kit (Invitrogen, Carlsbad, CA, USA) according to the manufacturer's instructions.

\section{Quantitative Real-Time RT-PCR}

Oligonucleotides for PRAME and the endogenous gene, HPRT, were designed using Primer Express Software from Applied Biosystems (Foster City, CA, USA), warranting that forward and reverse sequences were in different exons. Primer sequences were as follows $\left(5^{\prime}\right.$ 3'): PRAME Forward: CTGTACTCATTTCCAGAGCCAGA, PRAME Reverse: TATTGAGAGAGGGTTTCCAAGGGGTT, HPRT (hypoxanthine-guanine phosphoribosyl transferase) Forward: TGAGGATTTGGAAAGGGTGT and HPRT Reverse: GAGCACACAGAGGGCTACAA.

We conducted a BLAST search to confirm the total gene specificity of the nucleotide sequences chosen for primers. Real-time PCR amplification and data analysis were performed using the ABI Prism 7500 Sequence Detector System Applied Biosystems (Foster City, CA, USA). Each cDNA sample was mixed with $12 \mu$ of Mastermix (SYBR ${ }^{\circ}$ Green PCR Master Mix, Applied Biosystems). Cycling conditions consisted of two singles steps at $50^{\circ} \mathrm{C}$ and $95^{\circ} \mathrm{C}$ for $2 \mathrm{~min}$ and $10 \mathrm{~min}$ respectively, followed by 40 cycles of amplification at $95^{\circ} \mathrm{C}$ for $15 \mathrm{~s}$ and at $60^{\circ} \mathrm{C}$ for $1 \mathrm{~min}$ for annealing and elongation. Experiments were 
performed in triplicate for both target genes and the endogenous gene. For each sequence, a standard curve was constructed to determine the assay sensitivity. The data were averaged from the values obtained in each reaction. Relative expression was automatically calculated and analysed according to $2^{-\Delta \Delta \mathrm{Ct}}$ method described previously ${ }^{23}$. Relative quantification describes a real-time PCR experiment in which the gene of interest (PRAME) in one tumor sample is compared to same gene in normal tissue, as expression calibrator. HPRT was used as a housekeeping gene to normalize the relative expression level to provide an accurate comparison of gene expression between different samples. Expression of the housekeeping gene $H P R T$ served as an endogenous control in each assay performed. The PCR efficiencies of the two genes were comparable $(\geq 95 \%)$.

\section{Statistical analysis}

Statistical analyses were carried out using Graph Pad Prism 4 Program (San Diego, CA, USA). The t test was used to analyze the gene expression of each gene studied. The Mann-Whitney test was used to analysis the relationship between gene expressions and clinical characteristics. In all cases, $\mathrm{p}<0.05$ was considered statistically significant. Kaplan-Meier curves were used to evaluate survival.

\section{RESULTS}

All clinical variables are summarized in Table. Stages M1, M2 and M3 were included in just one group named $M+, 32 \%(n=12)$. In the M stage we found: stage M0, $68 \%$ $(n=25)$, stage $M 1,6 \%(n=2)$, stage M2, $13 \%(n=5)$ and $M 3$, $13 \%(n=5)$. Eighteen of 37 patients died from disease and 19 patients were disease-free or in treatment. The most of our samples were classic medulloblastoma (92\%).

PRAME was overexpressed in 31 (84\%) samples, median $33(\mathrm{p}=0.08)$ (cut-off $\geq 2$ ) (Figure). The differentially expressed genes were determined based on two criteria: gene performance outline filtering was applied to exclude the lower intensity or absent values, and only genes with fold changes larger than -2 and +2 were considered for increased/ decreased expression. Seventeen of 31 (55\%) was high risk, two (6\%) was anaplastic or large-cell/anaplastic subtype, 9 (29\%) was relapsed, 16 (52\%) were died, 8 (26\%) were metastatic $(\mathrm{M}+)$ stage, beyond that $12(39 \%)$ suffered partial resection of tumor. No statistical association was found between clinical features and PRAME expression. Likewise, there were no significant association with PRAME expression and Kaplan-Meier survival curves.

\section{DISCUSSION}

Medulloblastoma is the most common malignancy in children and it is highly aggressive $e^{3}$. In spite of the sophis-
Table. Clinical variable evaluated.

\begin{tabular}{lc}
\hline Clinical variable & Patients (\%) \\
\hline Classification & 57 \\
High risk & 43 \\
Low risk & \\
Stage & 67 \\
M0 & 32 \\
M+ & \\
Surgery & 54 \\
$\quad$ Total & 46 \\
Partial & \\
Follow-up & 57 \\
Death & 43 \\
Out or in treatment & \\
Relapse & 26 \\
Relapsed & 74 \\
Non relapsed & \\
\hline M0: no evidence of disseminated disease; M+: evidence of disseminated \\
disease.
\end{tabular}

PRAME expression

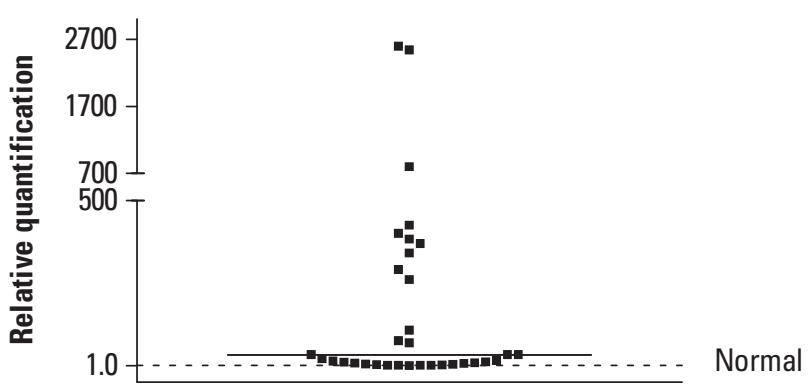

Figure. Representative results of PRAME expression for all samples studied. The PRAME expression in medulloblastoma fragments not showed statistical significance in relation to reference RNA ( $p=0.08)$. Black line is the median. Dotted line represents normal samples.

ticated techniques of neurosurgery, radiotherapy and chemotherapy, this tumor has a high mortality rate ${ }^{2,24}$ and the most of the survivors suffer from neurological development and growth deficit, and endocrine dysfunction ${ }^{1,25}$.

The identification of tumor-specific antigens, as $P R A M E$, can be an essential step in toward to cancer vaccines. $P R A M E$ is frequently expressed in melanomas, non-small cell lung carcinoma, breast carcinoma, renal cell carcinoma, head and neck cancer, Wilms' tumor and Hodgkin's lymphoma ${ }^{12,14,17-19}$. PRAME overexpression, in some type of solid tumors, is associated with aggressiveness of the tumor and poor clinical outcome $e^{18-21,26}$.

Usually gene expression profile can provide the key 
toward to find good tumor markers, hence we verified the gene expression of PRAME in MB samples by Realtime RT-PCR technique and compared the results with some clinical features. Although we did not have find any correlation between PRAME expression and the clinical variable studied, we find that $84 \%$ of patients presented high PRAME expression. We could not detect a correlation between PRAME expression in the tumor and clinicopathological parameters of the patients. Jacobs et al. ${ }^{28}$ proposed that vaccination of patients with tumor antigens is conceivable at all disease stages, including when a large tumor burden is present. Furthermore, considering that pediatric tumors tend to coexpress multiple antigen tumors, one may target several antigens in the same patient, which should reduce the risk of resistance through antigen-loss tumor variants ${ }^{27,28}$.

In general, it is rare to find data that allow clear association between expression of tumor-associated antigens and the outcome of patients ${ }^{29,30}$. Nevertheless, association of tumor-associated antigens with advanced diseases has been showed in a couple of studies ${ }^{29-30}$. Taken together, all this information plus our results, we can suggest that the remarkably higher levels of PRAME expression found in our samples can be an evidence of possible target therapeutic in cancer vaccines in medulloblastoma patients. However, the question about the ability of the patients to cause an immunological response to this antigen remains unknown.

Although there was no association between PRAME expression and clinical features of patients, $P R A M E$ gene could be a candidate for immunotherapy target using antibodies or inhibiter small molecules like anti-cancer agents, since it is highly expressed in medulloblastomas.

\section{REFERENCES}

1. Pizer B, Clifford S. Medulloblastoma: new insights into biology and treatment. Arch Dis Child Educ Pract Ed 2008;93:137-144.

2. Crawford JR, MacDonald TJ, Packer RJ. Medulloblastoma in childhood: new biological advances. Lancet Neurol 2007;6:1073-1085.

3. MacDonald TJ. Aggressive infantile embryonal tumors. J Child Neurol 2008; 23:1195-1204.

4. Caballero OL, Chen YT. Cancer/testis (CT) antigens: potential targets for immunotherapy. Cancer Sci 2009;100:2014-2021.

5. Oba-Shinjo SM, Caballero OL, Jungbluth AA, et al. Cancer-testis (CT) antigen expression in medulloblastoma. Cancer Immun 2008;8:7.

6. Ransohoff RM, Kivisakk P, Kidd G. Three or more routes for leukocyte migration into the central nervous system. Nat Rev Immunol 2003;3:569-581.

7. Galea I, Bernardes-Silva M, Forse PA, et al. An antigen-specific pathway for CD8 T cells across the blood-brain barrier. J Exp Med 2007;204:2023-2030.

8. Lampson LA. Brain tumor immunotherapy: an immunologist's perspective. J Neurooncol 2003:64:3-11.

9. Mackall CL, Fleisher TA, Brown MR, et al. Age, thymopoiesis, and CD4+
T-lymphocyte regeneration after intensive chemotherapy. N Engl J Med 1995; 332:143-149.

10. Heitger A, Greinix H, Mannhalter C, et al. Requirement of residual thymus to restore normal T-cell subsets after human allogeneic bone marrow transplantation. Transplantation 2000;69:2366-2373.

11. Jacobs JF, Grauer OM, Brasseur F, et al. Selective cancer-germline gene expression in pediatric brain tumors. J Neurooncol 2008;88:273-280.

12. van Baren $\mathrm{N}$, Chambost $\mathrm{H}$, Ferrant $\mathrm{A}$, et al. PRAME, a gene encoding an antigen recognized on a human melanoma by cytolytic $T$ cells, is expressed in acute leukaemia cells. Br J Haematol 1998;102:1376-1379.

13. Greiner J, Schmitt M, Li L, et al. Expression of tumor-associated antigens in acute myeloid leukemia: Implications for specific immunotherapeutic approaches. Blood 2006;108:4109-4117.

14. Steinbach D, Viehmann S, Zintl F, Gruhn B. PRAME gene expression in childhood acute lymphoblastic leukemia. Cancer Genet Cytogenet 2002; 138:89-91.

15. Steinbach D, Hermann J, Viehmann S, Zintl F, Gruhn B. Clinical implications of PRAME gene expression in childhood acute myeloid leukemia. Cancer Genet Cytogenet 2002;133:118-123.

16. Paydas S, Tanriverdi $K$, Yavuz $S$, et al. PRAME mRNA levels in cases with acute leukemia: clinical importance and future prospects. Am J Hematol 2005; 79:257-261.

17. Paydas S, Tanriverdi K, Yavuz S, Seydaoglu G. PRAME mRNA levels in cases with chronic leukemia: clinical importance and review of the literature. Leuk Res 2007:31:365-369.

18. Ikeda $H$, Lethe $B$, Lehmann $F$, et al. Characterization of an antigen that is recognized on a melanoma showing partial HLA loss by CTL expressing an NK inhibitory receptor. Immunity 1997;6:199-208.

19. Epping MT, Bernards R. A causal role for the human tumor antigen preferentially expressed antigen of melanoma in cancer. Cancer Res 2006;66:1063910642.

20. Oberthuer A, Hero B, Spitz R, Berthold F, Fischer M. The tumor-associated antigen PRAME is universally expressed in high-stage neuroblastoma and associated with poor outcome. Clin Cancer Res 2004;10:4307-4313.

21. Chang $\mathrm{CH}$, Housepian EM, Herbert C Jr. An operative staging system and a megavoltage radiotherapeutic technic for cerebellar medulloblastomas. Radiology 1969;93:1351-1359.

22. Giangaspero F, Eberhart CG, Haaspasalo H, et al. Medulloblastoma. In: Louis DMN, Ohgaki H, Wiestler OO, et al. (Eds.). WHO classification of tumors of central nervous system, $4^{\text {th }}$ edn.Lyon: IARC Press, 2007:132-140.

23. Livak KJ, Schmittgen TD. Analysis of relative gene expression data using real-time quantitative PCR and the 2(-Delta Delta $C(T)$ ) Method. Methods 2001;25:402-408.

24. Thomas PR, Deutsch M, Kepner JL, et al. Low-stage medulloblastoma: final analysis of trial comparing standard-dose with reduced-dose neuraxis irradiation. J Clin Oncol 2000;18:3004-3011.

25. Pfister S, Remke M, Benner A, et al. Outcome prediction in pediatric medulloblastoma based on DNA copy-number aberrations of chromosomes $6 q$ and $17 q$ and the MYC and MYCN loci. J Clin Oncol 2009;27:1627-1636.

26. Neumann $E$, Engelsberg A, Decker J, et al. Heterogeneous expression of the tumor-associated antigens RAGE-1, PRAME, and glycoprotein 75 in human renal cell carcinoma: candidates for T-cell-based immunotherapies? Cancer Res 1998;58:4090-4095.

27. Khong HT, Wang QJ, Rosenberg SA. Identification of multiple antigens recognized by tumor-infiltrating lymphocytes from a single patient: tumor escape by antigen loss and loss of MHC expression. J Immunother 2004;27:184-190.

28. Jacobs JF, Brasseur F, Hulsbergen-van de Kaa CA, et al. Cancer-germline gene expression in pediatric solid tumors using quantitative real-time PCR. Int J Cancer 2007;120:67-74.

29. Kavalar R, Sarcevic B, Spagnoli GC, et al. Expression of MAGE tumour-associated antigens is inversely correlated with tumour differentiation in invasive ductal breast cancers: an immunohistochemical study. Virchows Arch 2001;439:127-131.

30. van Baren N, Brasseur F, Godelaine D, et al. Genes encoding tumor-specific antigens are expressed in human myeloma cells. Blood 1999;94:1156-1164. 